\title{
Non-Newtonian Two-Phase Flow Characteristics across Sudden Expansion in Horizontal Rectangular Minichannel
}

\author{
Agus Santoso, Daiki Goto, Tomoaki Takehira, Ahmad Aslam, Akimaro Kawahara, \\ Michio Sadatomi \\ Department of Mechanical System Engineering, Graduate School of Science and Technology, Kumamoto \\ University, Kumamoto, Japan \\ Email: asmt07@gmail.com
}

Received 31 July 2016; accepted 26 August 2016; published 29 August 2016

Copyright (C) 2016 by authors and Scientific Research Publishing Inc.

This work is licensed under the Creative Commons Attribution International License (CC BY). http://creativecommons.org/licenses/by/4.0/

(c) (i) Open Access

\begin{abstract}
In the present paper, in order to clarity the effects of non-Newtonian liquid properties on the flow, similar experiments have been conducted for that of $0.4 \mathrm{wt} \%$ polyacrylamide (PAM) aqueous solutions as the working liquid, and air as the working gas. Liquid single-phase and air-liquid twophase flow experiments were conducted at room temperature using the horizontal rectangular mini-channel with a sudden expansion. The cross-sectional dimensions of the narrow channel upstream from the sudden expansion were $2.79 \mathrm{~mm}, 3.09 \mathrm{~mm}$ and $2.94 \mathrm{~mm}$ in the height $(H)$, the width $(W)$ and the hydraulic diameter $\left(D_{H}\right)$, while those for the wide channel were $2.95 \mathrm{~mm}, 5.98$ $\mathrm{mm}$ and $3.95 \mathrm{~mm}$. The pressure distributions in the channels upstream and downstream from the expansion were measured with calibrated pressure transducer to determine the pressure change due to the expansion. The flow pattern, the bubble velocity, the bubble length, and the void fraction were measured with a high-speed video camera. The flow pattern map is drawn from the observed flow pattern, i.e., bubble flow, slug flow and annular flow in both the wide and the narrow channels. The bubble length data were compared with the calculation by the scaling law proposed by Kanezaki $e t$ al. and Kawahara $e t$ al. The pressure change data at the expansion were compared with our previous data together with several correlations in literature. Results of such experiment and comparisons are reported in the present paper.
\end{abstract}

\section{Keywords}

Non-Newtonian, Two-Phase Flow, Sudden Expansion, Minichannel 


\section{Introduction}

Two-phase flows across singularities such as bend, contraction and expansion are commonly seen in piping of many industrial systems and/or devices. Recently the emergence of the micro chemical technology demands high efficient reactors with more compact structure, which have to consider gas/non-Newtonian fluid two-phase flow in micro- or mini-channels [1]. A number of researches have been reported on two-phase flows in small channel with singularities. Among them, Sadatomi et al. [2] investigated flow regime, pressure drop, bubble velocity and void fraction for air-water two phase flow through U-bend, sudden expansion and sudden contraction in rectangular minichannel. Kawahara et al. [3] conducted experimental investigations on gas-liquid two-phase flows in two kinds of rectangular microchannels with the width of in the larger channels upstream from the contraction were 0.53 or $0.78 \mathrm{~mm}$ at $0.230 \mathrm{~mm}$ in height, while that in the smaller ones was $0.270 \mathrm{~mm}$ at $0.230 \mathrm{~mm}$ in height. To know the effects of liquid properties, the test liquids were changed as distilled water, ethanol $49 \mathrm{wt} \%$ aqueous solution, pure ethanol and Hydrofluoroether (HFE)-7200 while the test gas was fixed as nitrogen gas. Abdelall et al. [4] performed an experimental study of pressure drop cause by abrupt flow area changes in small circular channels. The larger and smaller tube diameters were 1.6 and $0.84 \mathrm{~mm}$, respectively. Deionized water and air were used as two-phase flow mixture. Chen et al. [5] conducted experimental investigation of the twophase flow characteristics across sudden contraction using air and water mixture. The contraction test section was from small rectangular channels of $3 \times 6 \mathrm{~mm}$ and $3 \times 9 \mathrm{~mm}$ to a small circular tube of $3 \mathrm{~mm}$ i.d. Padilla et al. [6] conducted experimental studies on two-phase flow of HFO-1234yf, R-134 and R-410A in a $10 \mathrm{~mm}$ glass tube with a cross-section area ratio of 0.49 . The experimental pressure drop data were used to test six prediction methods from literatures.

However, as far as we know the studies on gas and non-Newtonian liquid two-phase flows across singularities in minichannel are still limited. Non-Newtonian fluids, such as paint, milk, toothpaste, animal blood, etc. are ubiquitous in nature, and they are often encountered in many industries, like in chemical engineering, bio-chemichal engineering, food processing, oil exploration, and medical engineering [7]. Fu et al. [7] observed the flow patterns of Newtonian/non-Newtonian fluids two-phase flow in T-shaped rectangular microchannels by using a high-speed camera. Three different dimensions of microchannels were employed with $400 \mu \mathrm{m} \times 400 \mu \mathrm{m}$, $400 \mu \mathrm{m} \times 600 \mu \mathrm{m}$, and $400 \mu \mathrm{m} \times 800 \mu \mathrm{m}$ in depth and width, respectively. The cyclohexane was used as the dispersed phase, and various concentrations of Carboxymethyl Cellulose (CMC) aqueous solutions as the continuous phase. Link et al. [8] realized a numerical investigation of an elasto-viscoplastic thixotropic fluid flowing through a 1:4 plane expansion using a recently proposed constitutive equation. The conservation equations were solved using a four-field Galerkin least-squares formulation in terms of the extra stress, pressure, velocity, and structure parameter, i.e., a scalar quantity that represents the structuring level of the material microstructure. The focus is on determining the effect of thixotropy, elasticity and viscoplasticity on the topology of yielded and unyielded regions of the expansion, on the field of structuring level, and on the field of elastic strain.

Li et al. [9] developed a model which predicts liquid holdup $\left(\varepsilon_{T P L}\right)$, pressure gradient and frictional multiplier $\left(\varnothing_{L}\right)$ for non-Newtonian liquid-gas flow with different interfacial shapes. The interfacial shape was calculated by solving the Young-Laplace equation, by assuming the non-Newtonian liquid as a power-law shear-thinning liquid. The results showed that the interfacial shape can be assumed as an arc shape when Bond number was lower than 10. The model can predict liquid holdup, two-phase pressure gradient and frictional multiplier for uniform stratified flows. The result also indicates that the interfacial effects on the holdup and pressure difference between two phases were significant, especially for small liquid holdups. Picchi et al. [10] studied flow pattern transition, pressure gradient, hold-up predictions in gas/non-Newtonian power-law fluid stratified flow. Pressure gradient and hold-up were predicted by two different theoretical approaches: the steady fully developed two-fluid model and the pre-integrated model. The theoretical predictions were compared with experimental data available for horizontal and for slightly downward inclined air/shear thinning fluid stratified flow taken from literature. The predictions of the pre-integrated model were validated showing a good agreement when compared with experimental data. Tang et al. [11] conducted experimental investigations on single-phase non-Newtonian liquid flow in microchannels. Experiments were conducted using deionized water and the PAM solution over a wide range of Reynolds numbers as the test liquids and fused silica microtubes with diameters from 75 to $250 \mu \mathrm{m}$, fused silica square microchannels with equivalent diameters of 75 and $100 \mu \mathrm{m}$, and stainless steel microtubes with diameters from 120 to $300 \mu \mathrm{m}$ as the test channels. They obtained mass flow rate and friction factor data for deionized water in smooth fused silica microchannels, and the data were in good agreement with 
theoretical predictions for conventional-sized channels while the deviation was observed for the data in stainless steel microtubes due to the roughness.

Mansour et al. [12] performed an experimental study of non-Newtonian two-phase flow through microchannel having hydraulic diameter of $0.25 \mathrm{~mm}$ as the test channel. Distilled water, and 3 types of polyacrylamide aqueous solutions (PAM $0.1 \mathrm{wt} \%$, PAM $0.2 \mathrm{wt} \%$ and PAM $0.4 \mathrm{wt} \%$ ) were used as working liquids, while nitrogen gas as the working gas. The pressure drop data can be accurately predicted by Lockhart-Martinelli method with a newly developed two-phase friction multiplier as function of void fraction and rheological flow index. Yang et al. [1] conducted experimental investigation on nitrogen/non-Newtonian fluid two-phase flow in vertical noncircular microchannels. Square and triangular cross-sectional channels with 2.5, 2.886 and 0.866 $\mathrm{mm}$ in hydraulic diameters were used. Three non-Newtonian aqueous solutions with typical rheological properties, i.e., 0.4\% Carboxymethyl Cellulose (CMC), 0.2\% Polyacrylamide (PAM) and 0.2\% Xanthan Gum (XG) were chosen as the working fluids. The rheological properties of the non-Newtonian fluids and geometrical factors were found to affect flow pattern transitions. Goto et al. [13] investigated pressure drop for gas and PAM $0.4 \mathrm{wt} \%$ liquid two-phase flows through sudden expansion in horizontal rectangular minichannel. The experimental data on pressure change at the expansion were compared with the some literatures.

Recently, Santoso et al. [14]-[16] in our group have investigated two-phase flow characteristic in rectangular minichannel with sudden expansion and sudden contraction in a horizontal plane. The cross-sectional sizes of the channel were from $3.09 \mathrm{~mm}$ by $2.79 \mathrm{~mm}$ to $5.98 \mathrm{~mm}$ by $2.95 \mathrm{~mm}$ for the sudden expansion and vice versa for the sudden contraction. They used water and viscoelastic liquid of $0.1 \mathrm{wt} \%$ PAM aqueous solution as the working liquid, while air as the working gas.

In the present study, following to Santoso et al.'s studies mentioned above, experiments have been conducted with air and PAM $0.4 \mathrm{wt} \%$ as the working fluid and the same rectangular minichannel with the area ratio of $\sigma_{A}=$ 0.49 as the test channel. The objective of the present study is to clarify the effects of non-Newtonian viscoelastic liquid on the characteristics of flow through sudden expansion for both single-phase and two-phase flows. Data for the experimental results obtained from air-PAM $0.4 \mathrm{wt} \%$ system will be compared with previous data for air-water and air-PAM $0.1 \mathrm{wt} \%$ flow and those from the other researchers in literatures.

\section{Experiments}

A schematic diagram of the test facility in the present study is shown in Figure 1, being the same as that used in our previous study [13]-[16]. Pressurized air from a compressor pushed the test liquid in a tank and supplies it to the test channel. Thus, no mechanical pump was used in the present experiment to avoid pulsation by the pump and also to avoid contamination by the pump. Figure 2 shows a schematic diagram of test channel with sudden expansion placed on a horizontal plane. The test channel had a rectangular cross-section and made of transparent acrylic resin for visual observation. The port \#1 was the liquid inlet port, while the port \#2 was the gas inlet ports. Therefore, two phases were supplied through the section 1 as a gas-liquid mixer.

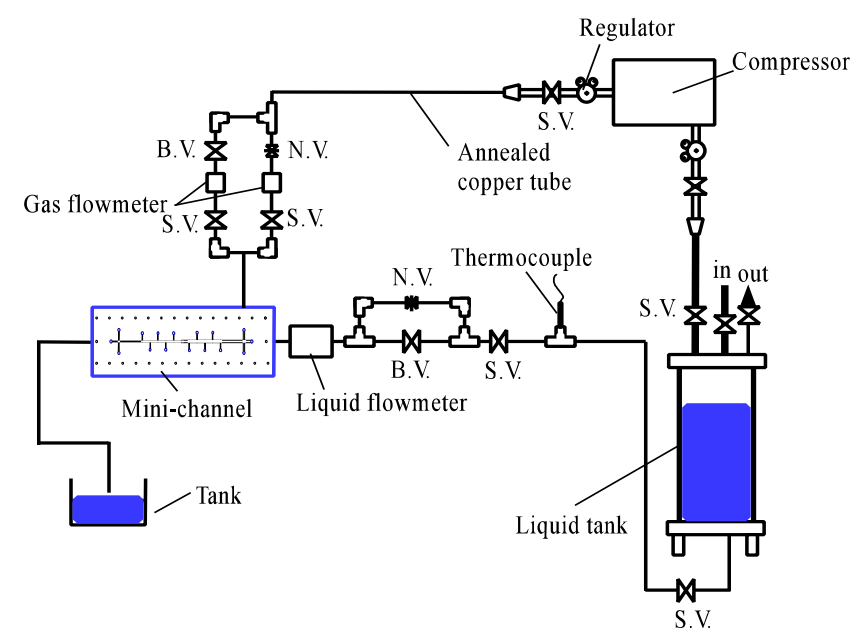

Figure 1. Test apparatus. 


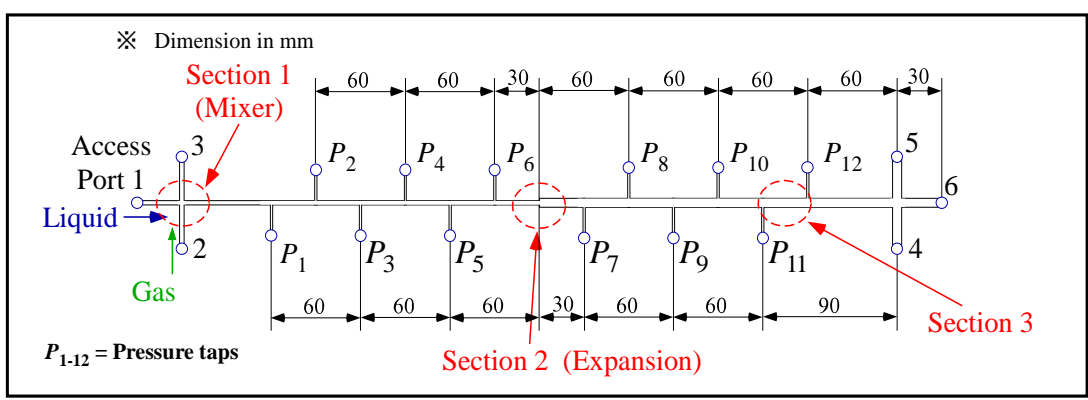

Figure 2. Test channel with sudden expansion.

The port \#6 was the gas-liquid mixture outlet to atmosphere. The port \#3, \#4 and \#5 were closed in the present experiment. It is noted that if port \#4 and \#6 were used as the inlet ports of gas and liquid, and port \#5, $\# 2$ and\#3 were closed, the sudden contraction test can be conducted with the same test channel. $P_{1}$ to $P_{12}$ were the pressure taps, and the pressure at $P_{4}$ was measured with a gauge type pressure transducer (Yokogawa, FP101-L31-L20). The pressures at other pressure taps were determined from the difference in pressure between the respective taps and $P_{4}$ tap measured with a differential pressure transducer (Validyne, DP15-32 or DP15-26 depending on the pressure range). The accuracy of the pressure measurement was within $3.5 \mathrm{~Pa}$ from a calibration test.

Volume flow rate of air was measured with a flow meter (KEYENCE, FD-A10 or FD-A1 depending on the flow rate range) within $2 \%$, while that of water with a flow meter (KEYENCE, FD-S) within $1 \%$. In order to obtain accurate time averaged values of air and water flow rates and pressures, the output signals from the respective sensors were fed to a personal computer via A/D converter over $10 \mathrm{sec}$. usually at $1 \mathrm{kHz}$.

Table 1 shows the cross-sectional dimensions of the test channel. The width $(W)$, the height $(H)$ and the hydraulic diameter $\left(D_{H}\right)$ for the wide channel were $3.09 \mathrm{~mm}, 2.79 \mathrm{~mm}$ and $2.94 \mathrm{~mm}$, while those for the narrow channel were $5.98 \mathrm{~mm}, 2.95 \mathrm{~mm}$ and $3.95 \mathrm{~mm}$, thus the area ratio $\sigma_{A}$ is about 0.49 . In this study, water and aqueous solution of $0.1 \mathrm{wt} \%$ and $0.4 \mathrm{wt} \%$ polyacrylamide (PAM) were selected as the working liquid, while air as the working gas at room temperature. Polyacrylamide aqueous solution is known as a kind of non-Newtonian fluid having viscoelasticity dispensable [17]. Also, PAM aqueous solution has shear thinning effect where the apparent viscosity decreases with increasing of the shear rate and is often expressed by the Ostwald-de Waele power law model as follows:

$$
\tau=K(\mathrm{~d} u / \mathrm{d} y)^{n}=K\left(\frac{\mathrm{d} u}{\mathrm{~d} y}\right)^{n-1} \frac{\mathrm{d} u}{\mathrm{~d} y}=\mu_{a} \frac{\mathrm{d} u}{\mathrm{~d} y}
$$

where $\tau$ is the wall shear stress, $\mathrm{d} u / \mathrm{d} y$ is the shear rate, $K$ is the consistency coefficient, $n$ is the flow index and $\mu_{a}$ is the apparent viscosity. In this study, the values of $K$ and $n$ were determined with a capillary method [18]. The $n$ and $K$ determined as well as the density, the surface tension for the test liquids used in the present and the previous studies are listed in Table 2. $n$ for both water and PAM aqueous solution were investigated within the share rate range of 80 to 12000 1/s.

For single-phase flow experiments, the ranges of Reynolds number ( $=\frac{\rho u D_{H}}{\mu_{a}}, u$ where is the mean velocity, $\mu$ the apparent viscosity) in the narrow channel $R e_{N}$ are from 320 to 9600 for water, and from 290 to 5900 for PAM aqueous solution. For two-phase flow experiments, the ranges of volumetric fluxes of liquid and gas are $0.1<j_{L}<2.3 \mathrm{~m} / \mathrm{s}$ and $0.1<j_{G}<10 \mathrm{~m} / \mathrm{s}$.

\section{Result and Discussion}

\subsection{Data Reduction}

Figure 3(a) and Figure 3(b) show examples of pressure distribution data obtained for a PAM 0.4 wt $\%$ single-phase flow and an air-PAM $0.4 \mathrm{wt} \%$ aqueous solution two-phase flow. The ordinate is the gauge pressure, while the abscissa is the distance from the singularity. The total pressure change across sudden expansion, $\Delta p_{e}$, 
Table 1. Dimensions of test channel cross section.

\begin{tabular}{cccc}
\hline & $\boldsymbol{W}[\mathbf{m m}]$ & $\boldsymbol{H}[\mathrm{mm}]$ & $\boldsymbol{D}_{\boldsymbol{H}}[\mathrm{mm}]$ \\
\hline Narrow, N & 3.09 & 2.79 & 2.94 \\
Wide, W & 5.98 & 2.95 & 3.95 \\
\hline
\end{tabular}

Table 2. Physical properties of test liquids.

\begin{tabular}{|c|c|c|c|c|}
\hline & $K\left[\right.$ Pa.s $\left.{ }^{\mathrm{n}}\right]$ & $n$ & $\rho\left[\mathrm{kg} / \mathrm{m}^{3}\right]$ & $\sigma[\mathbf{N} / \mathbf{m}]$ \\
\hline Water & 0.00095 & 1.00 & 998 & 0.073 \\
\hline PAM 0.1 wt $\%$ & 0.00151 & 1.00 & 998 & 0.072 \\
\hline PAM 0.4wt $\%$ & 0.0134 & 0.85 & 999 & 0.072 \\
\hline
\end{tabular}

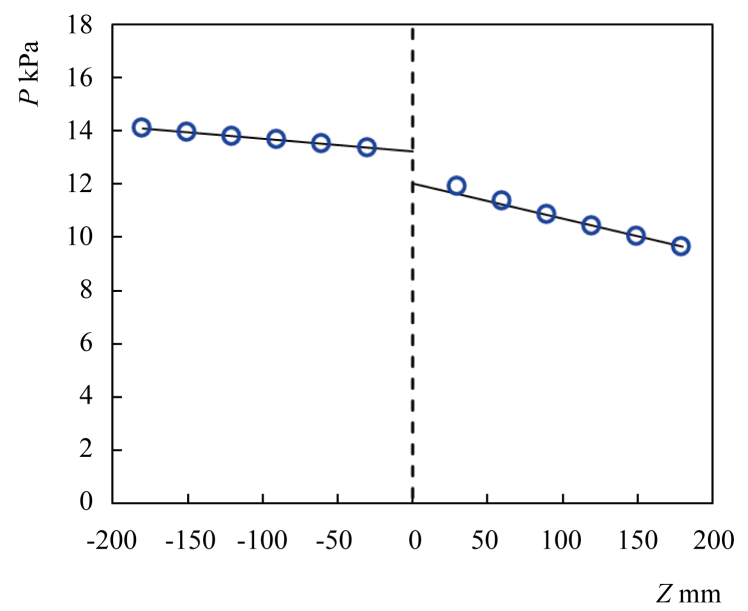

(a)

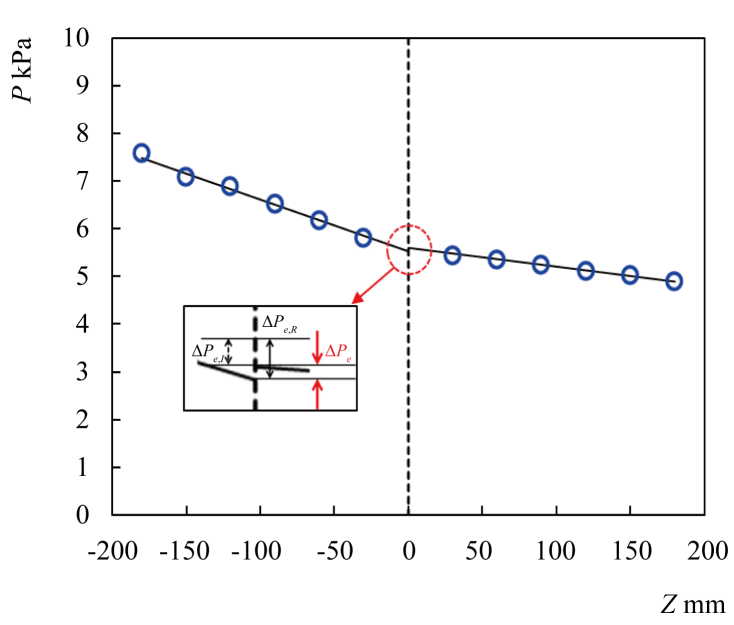

(b)

Figure 3. Pressure distribution along the channels upstream and downstream from expansion. (a) Single-phase flow for PAM $0.4 \mathrm{wt} \%\left(R e_{N}=900\right)$; (b) Two-phase flow for PAM $0.4 \mathrm{wt} \%\left(j_{G}=0.1 \mathrm{~m} / \mathrm{s}, j_{L}=0.5 \mathrm{~m} / \mathrm{s}\right)$.

was determined by the extrapolations of the axial pressure profiles upstream and downstream from the expansion. $\Delta p_{e}$ consists of the irreversible and reversible pressure drop, and could be expressed by the following Kays's equation (Kays, [19]):

$$
\begin{aligned}
& \Delta p_{e}=\frac{\rho u_{N}^{2}}{2}\left(k_{e}+\sigma_{A}^{2}-1\right) \\
& \sigma_{A}=\frac{A_{N}}{A_{W}}
\end{aligned}
$$

where $\rho$ is the density of the working fluid, $u_{N}$ the mean velocity in the narrow channel, $K_{e}$ the expansion loss coefficient, $A_{N}$ the cross section area of the narrow channel, $A_{w}$ the cross section area of the wide channel and $\sigma_{A}$ the area ratio.

In order to check the accuracy of the pressure measurement, the single-phase friction factor data were determined from the fully developed pressure gradient data in the upstream and the downstream channels. Figure 4(a) and Figure 4(b) show the Darcy friction factor data, respectively for the channels upstream and downstream of the singularity. The data are plotted against the Reynolds number, based on the hydraulic diameter. The present data in turbulent flow are compared with calculated curve by Sadatomi et al. [20], while those in laminar flow with calculated curve by Shah and London [21] which is a function of aspect ratio, $\alpha^{*}(=W / H)$, for rectangular channels: 


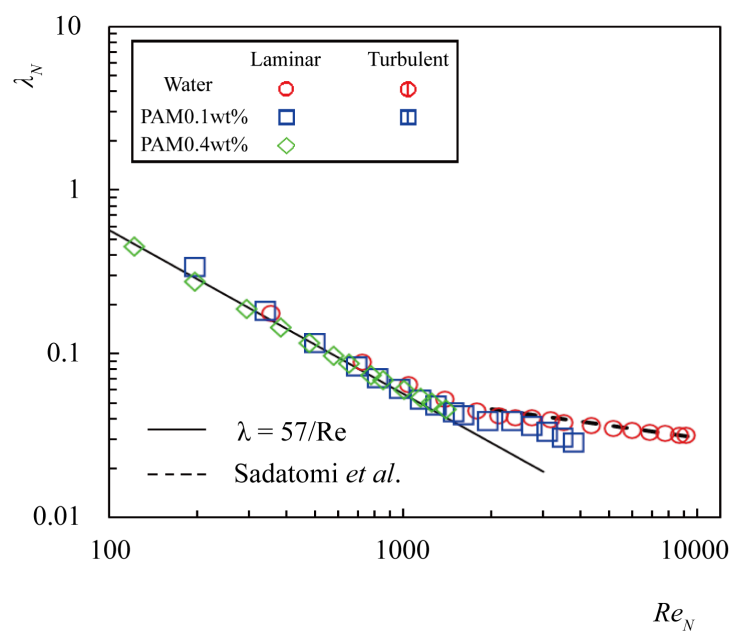

(a)

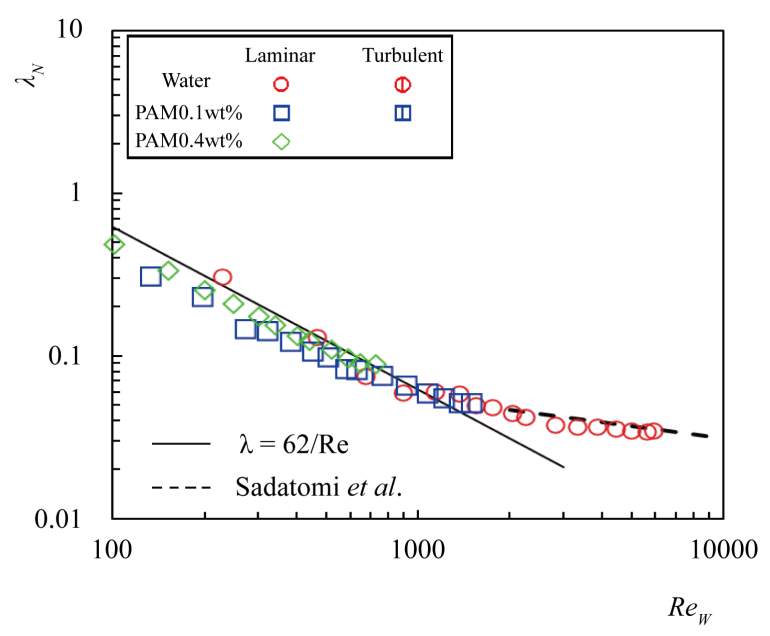

(b)

Figure 4. Friction factor data in the channels (a) upstream and (b) downstream from the expansion. (a) $\lambda_{N}$ vs. $\operatorname{Re}_{N}$ (Upstream, $\mathrm{W}=3 \mathrm{~mm}$ ); (b) $\lambda_{W}$ vs. $R e_{W}$ (Downstream, $\mathrm{W}=6 \mathrm{~mm}$ ).

$$
\lambda R e=96\left(1-1.3553 \alpha^{*}+1.9467 \alpha^{* 2}-1.7012 \alpha^{* 3}+0.9564 \alpha^{* 4}-0.2537 \alpha^{* 5}\right)
$$

Most data beside the data of PAM $0.1 \mathrm{wt} \%$ in laminar flows agree very well to the two curves, and the accuracy of pressure measurement in the present study for PAM $0.4 \mathrm{wt} \%$ was confirmed.

\subsection{Flow Pattern in Two-Phase Flow}

Figure 5(a) and Figure 5(b) show the flow pattern map for the test channels upstream and downstream from the expansion in the present experiment. The ordinate and abscissa are the volumetric fluxes of liquid (water and PAM) and air. In the channel upstream, the bubble flow region for the PAM 0.4 wt\% aqueous solution is narrower compared to both water and PAM 0.1 wt\% aqueous solution. This is due to the higher liquid viscosity, causing thicker liquid film between the bubble slug and the channel wall in the PAM 0.1 wt\% aqueous solution than water.

Figures 6(a)-(c) show typical flows in the test channel of air-PAM $0.4 \mathrm{wt} \%$ aqueous solution flow, respectively for a bubbly flow at $j_{G N}=0.1 \mathrm{~m} / \mathrm{s}, j_{L N}=0.5 \mathrm{~m} / \mathrm{s}$, a slug flow at $j_{G N}=0.5 \mathrm{~m} / \mathrm{s}, j_{L N}=0.5 \mathrm{~m} / \mathrm{s}$ and an annular flow at $j_{G N}=10 \mathrm{~m} / \mathrm{s}, j_{L N}=0.5 \mathrm{~m} / \mathrm{s}$. Three pictures were taken from the top of the channel, respectively at section 1, 2 and 3. After passing through the sudden expansion, the formation of vortex can be seen in figures (b) and (c). By the vortex formation, the energy loss most occur at a region just downstream from the sudden expansion.

\subsection{Bubble Velocity and Void Fraction in Two-Phase Flow}

Figure 7 shows the bubble velocity data, $u_{G}$, in the present experiment against the total volumetric flux of liquid and gas, $j\left(=j_{L}+j_{G}\right)$. Bubble velocity data for both the narrow channel and the wide channel upstream and downstream from the expansion are simultaneously plotted. The solid line of $u_{G}=j$ is applicable to homogenous flows. The dashed lines indicates the velocity when all bubbles concentrate at the channel axis in turbulent liquid flow in circular channel, while the dot dash line indicates that when all bubbles concentrate there in laminar liquid flow between parallel flat plates. The highest velocities are recorded by the PAM $0.4 \mathrm{wt} \%$ aqueous solution. This is due to the highest viscosity among the three test liquids, causing thicker liquid film between the bubble slugs and the channel wall, and reducing the flow area of the bubbles.

Figure 8 shows a comparison of bubble velocity between experiment and calculation by the drift flux model of Zuber and Findlay [22], Equation (5), together with Equations (7) and (8). The calculations agree with the data within root mean square errors of $20 \%$.

$$
u_{G}=C_{0} j+V_{G j}
$$




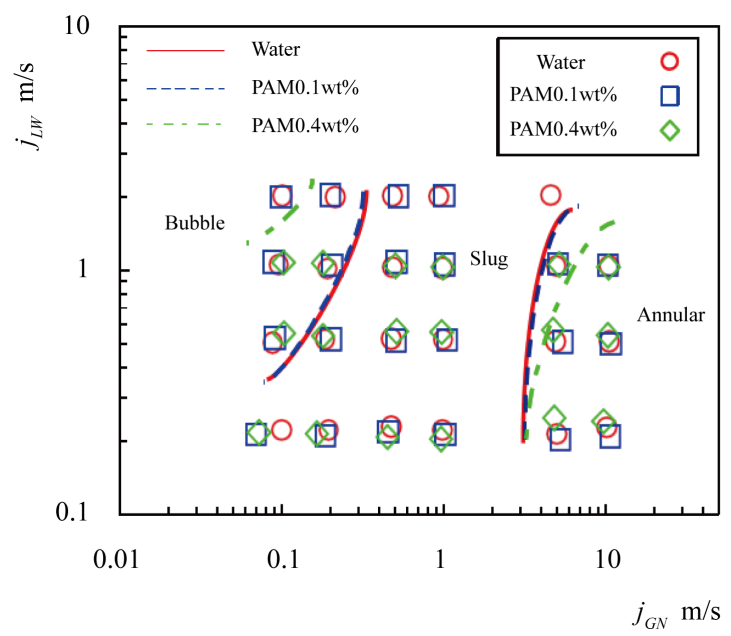

(a)

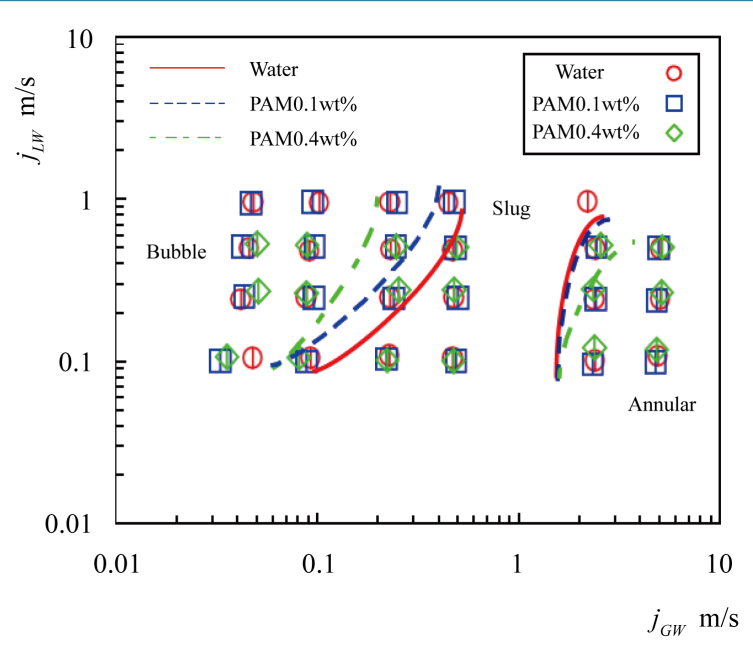

(b)

Figure 5. Flow pattern map. (a) Upstream (W= $3 \mathrm{~mm}$ ); (b) Downstream (W= $6 \mathrm{~mm}$ ).
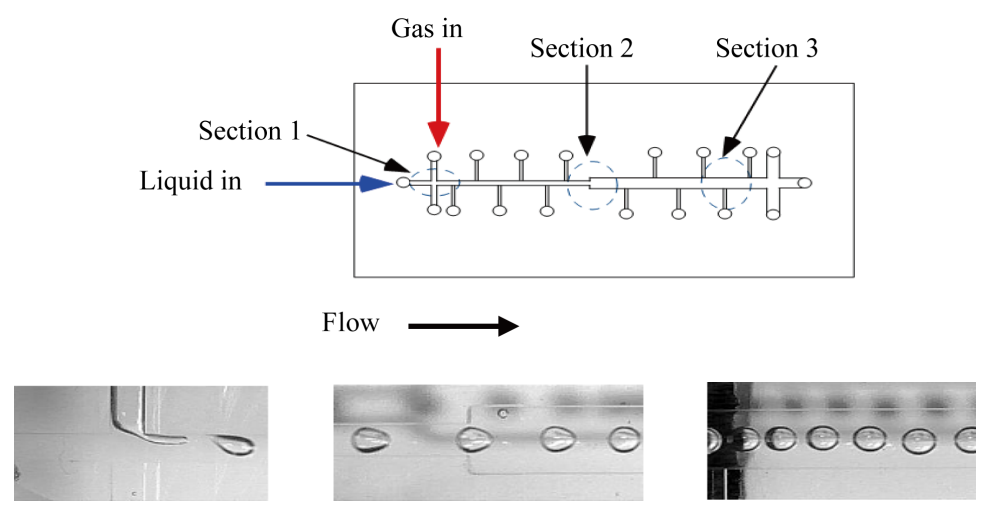

(a)
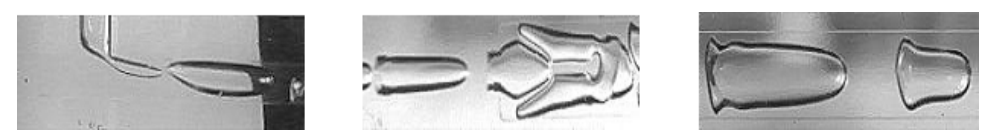

(b)
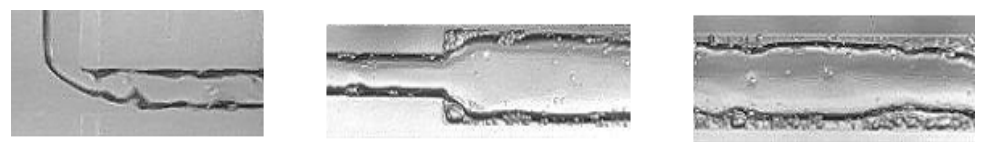

(c)

Figure 6. Flow pattern (air-PAM 0.4 wt $\%$ aqueous solution). (a) Bubble flow ( $j_{G N}=0.1 \mathrm{~m} / \mathrm{s}, j_{L N}=0.5 \mathrm{~m} / \mathrm{s}$ ); (b) Slug flow $\left(j_{G N}=0.5 \mathrm{~m} / \mathrm{s}, j_{L N}=0.5 \mathrm{~m} / \mathrm{s}\right)$; (c) Annular flow $\left(j_{G N}=10 \mathrm{~m} / \mathrm{s}, j_{L N}=0.5 \mathrm{~m} / \mathrm{s}\right)$.

Here, the drift velocity, $V_{G j}$ was taken as zero because of horizontal flow. The distribution parameter, $C_{0}$, was determined based on the microchannel flow data by Kawahara's correlation [23].

$$
C_{0}=3.87 B o^{0.19} \operatorname{Re}_{L}^{-0.01} W e_{G}^{0.01}
$$

Here, $B o$ is the Bond number, $R e_{L}$ the liquid Reynolds number and $W e_{G}$ the gas Weber number. Miyagawa $e t$ $a l$. [24] modified the distribution parameter, $C_{0}$ based on the data for rectangular mini-channel having the hydrodynamic diameters of $D_{H}=3 \mathrm{~mm}$ and $4 \mathrm{~mm}$.

$$
C_{0}=1.28 B o^{0.19} \mathrm{Re}_{L}^{-0.01} W e_{G}^{0.01} \text { for } D_{H}=3 \mathrm{~mm}
$$




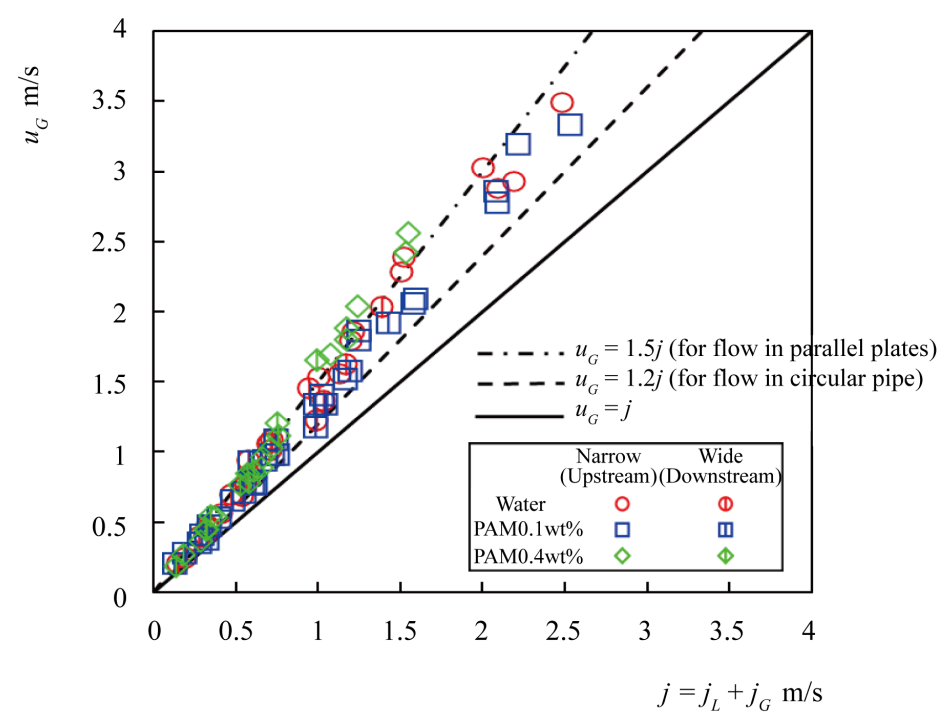

Figure 7. Bubble velocity ( $u_{G}$ vs. $j$ ).

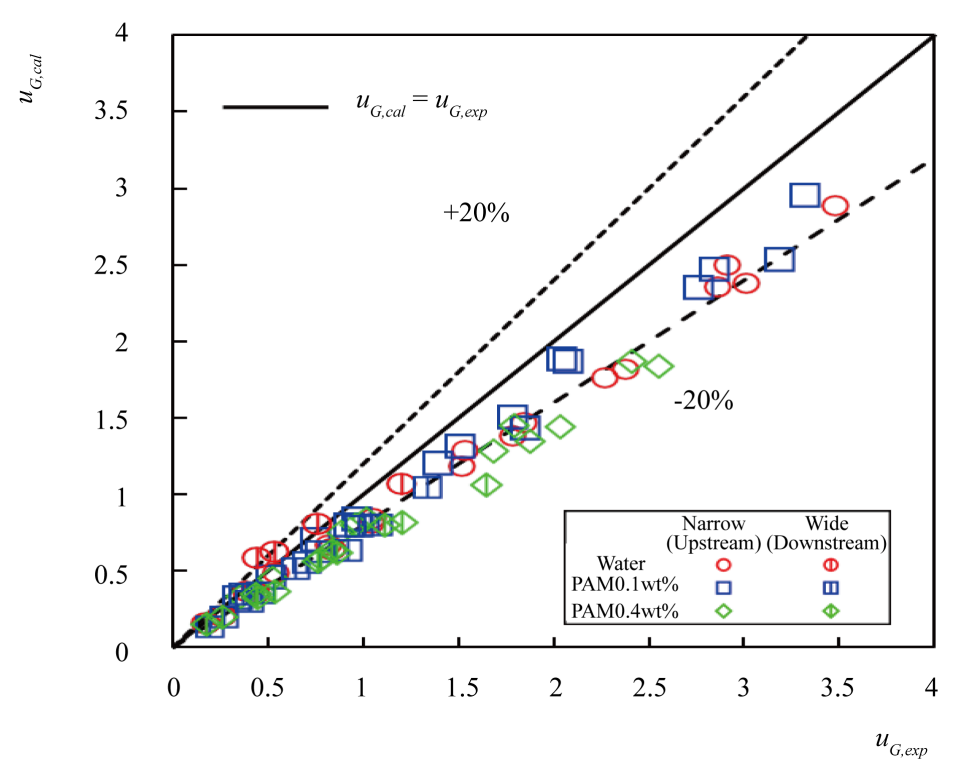

Figure 8. Comparison of bubble velocity between experiment and calculation by drift flux model with $C_{0}$ correlations by Miyagawa et al. [27] $\left(u_{G, c a l}\right.$ vs. $\left.u_{G, \exp }\right)$.

$$
C_{0}=1.02 B o^{0.19} \operatorname{Re}_{L}^{-0.01} W e_{G}^{0.01} \text { for } D_{H}=4 \mathrm{~mm}
$$

Figure 9 shows the void fraction data, $\alpha$, in the present experiment against the gas-phase volume flow rate fraction, $\beta=j_{G} /\left(j_{G}+j_{L}\right)$. The solid line of $\alpha=\beta$ is applicable to homogeneous flow, and the dashed lines represents the Armand's correlation [25], $\alpha=0.833 \beta$. The $\alpha$ data for the air-water flows agree reasonably with the calculation by Armand's correlation [25], but the data for the present air-PAM 0.4 wt $\%$ flows are about $20 \%$ lower than those for the air-water flows.

Six correlations developed for macro, mini and micro-channels are examined to validate their suitability against the present void fraction data. Table 3 and Table 4 list the mean error, $\varepsilon_{M}$, and the RMS error, $\varepsilon_{R M S}$, for the respective correlations in the upstream and the downstream channel data. The mean error and the RMS error are defined as: 


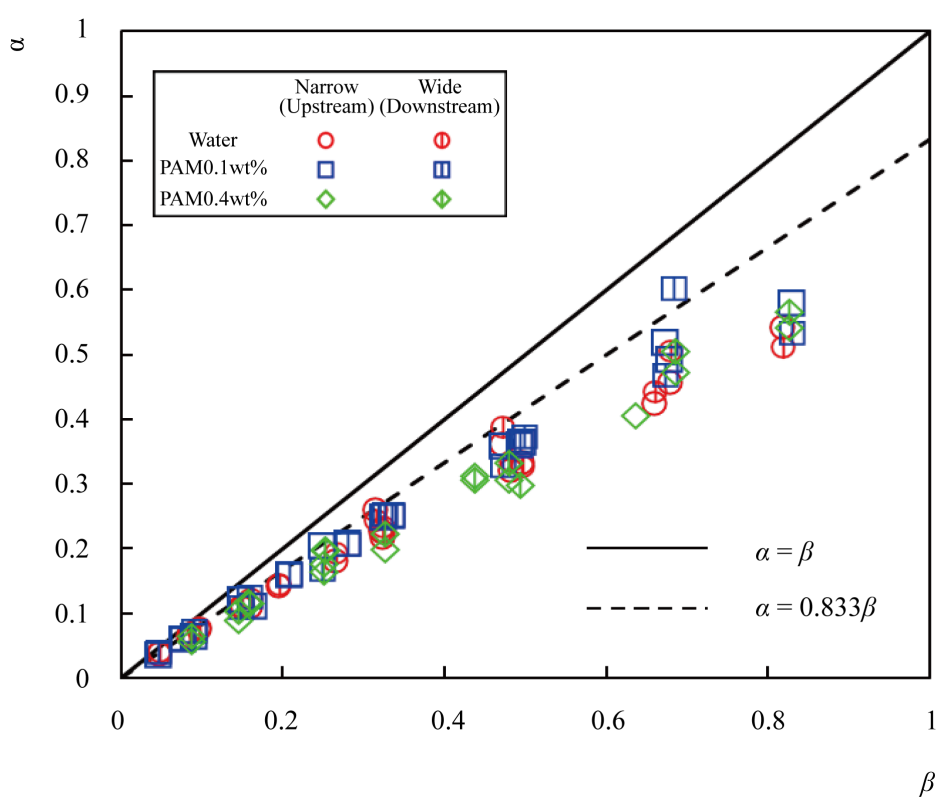

Figure 9. Void fraction ( $\alpha$ vs. $\beta$ ).

Table 3. RMS and mean values of errors for void fraction in narrow channel.

\begin{tabular}{lcc}
\hline Correlation & $\boldsymbol{\varepsilon}_{M} \%$ & $\varepsilon_{R M S} \%$ \\
\hline Armand [25] & 24.8 & 31.6 \\
Spedding-Chen [26] & 24.9 & 31.6 \\
Mishima-Hibiki [27] & 17.7 & 23.4 \\
Zhang et al. [28] & 15.8 & 21.4 \\
Modefied Kawahara et al. [29] & 4.1 & 9.9 \\
Schmidt and Friedel [30] & -0.6 & 11.1 \\
\hline
\end{tabular}

Table 4. RMS and mean values of errors for void fraction in wide channel.

\begin{tabular}{lcc}
\hline Correlation & $\boldsymbol{\varepsilon}_{M} \%$ & $\boldsymbol{\varepsilon}_{\boldsymbol{R} M S} \%$ \\
\hline Armand [25] & 18.6 & 20.3 \\
Spedding-Chen [26] & 18.6 & 20.4 \\
Mishima-Hibiki [27] & 15.6 & 17.6 \\
Zhang et al. [28] & 14.0 & 16.2 \\
Modefied Kawahara et al. [29] & 22.1 & 23.4 \\
Schmidt and Friedel [30] & 17.4 & 20.7 \\
\hline
\end{tabular}

$$
\begin{aligned}
& \varepsilon_{M}=\left[\frac{1}{n} \sum_{i=1}^{n} \frac{\alpha_{c a l}-\alpha_{\text {exp }}}{\alpha_{\text {exp }}}\right] \times 100 \% \\
& \varepsilon_{R M S}=\left[\sqrt{\frac{1}{n-1} \sum_{i=1}^{n}\left(\frac{\alpha_{c a l}-\alpha_{\text {exp }}}{\alpha_{\text {exp }}}\right)^{2}}\right] \times 100 \%
\end{aligned}
$$


Of these, modified Kawahara et al. [29] and Schmidt \& Friedel's correlations [30] give better prediction than others for the narrow channel, while Zhang et al.'s correlation [28] for the wide channel.

\subsection{Bubble Length}

Figure 10(a) shows the data on the ratio of bubble length to unit cell length $L$ ( $=L_{G}+L_{L} ; L_{L}$ is the liquid slug length) against the void factor, $\alpha$. The solid line is calculated by Kanezaki et al.'s correlation [31] applicable to vertical upward air-water flows in $26 \mathrm{~mm}$ i.d. pipe.

$$
\frac{L_{G}}{L}=1.5 \alpha-0.2
$$

Almost all of the experimental data are higher than the solid line and the dashed lines $\left(L_{G} / L=1.5 \alpha\right)$. In addition, the data for the wide channel are higher than those for the narrow channel. Concerning $L_{G} / L$, Kawahara et al. [29] proposed Equation (12) for horizontal two-phase flows in a rectangular microchannel. Where $\beta$ is the homogeneous void fraction, $\beta\left(=j_{G} /\left(j_{G}+j_{L}\right)\right)$, Figure 10(b) compares our data to the calculation by Equation (12).

$$
\frac{L_{G}}{L}=\frac{0.9 \beta^{0.68}}{1-0.1 \beta^{0.005}}
$$

The data for the wide channel are higher than those for the narrow channel, especially for PAM 0.4 wt $\%$ aqueous solution.

\subsection{Pressure Change across Expansion}

The experiment on the single-phase pressure change at expansion, $\Delta P_{e}$, are plotted against the mean velocity of liquid in narrow channel, $u_{L N}$ in Figure 11. $\Delta P_{e}$ for both the water flow and the PAM flow increase with $u_{L N}$. This is mainly by the increase in the reversible pressure rise, $\Delta P_{e, R}$, than the irreversible pressure drop, $\Delta P_{e, I}$. For PAM 0.4 wt\%, $\Delta P_{e}$ were higher than that of water. From the $\Delta P_{e}$, data the coefficient of the irreversible expansion in single-phase liquid flow, $k_{e, I}$, was calculated using Equation (13).

$$
k_{e, I}=\frac{\Delta P_{e, R}-\Delta P_{e}}{\frac{\rho u_{N}^{2}}{2}}
$$

here,

$$
\Delta P_{e, R}=\frac{\rho u_{N}^{2}}{2}\left(\sigma_{A}^{2}-1\right)
$$

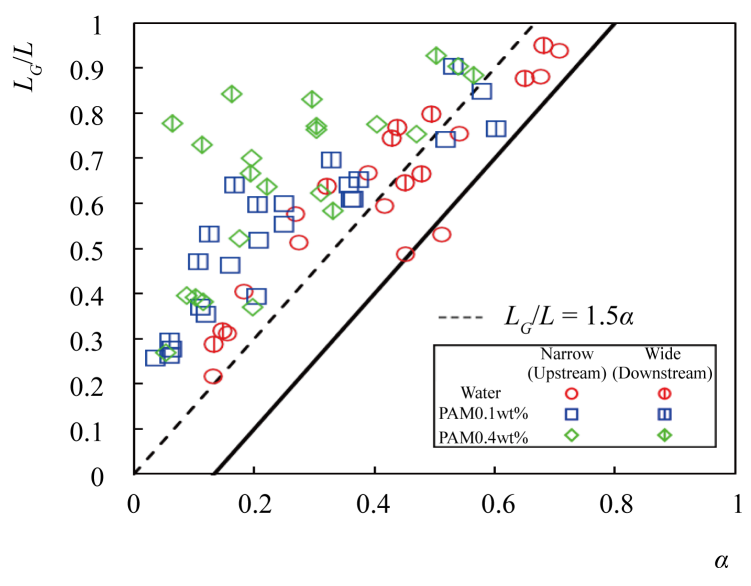

(a)

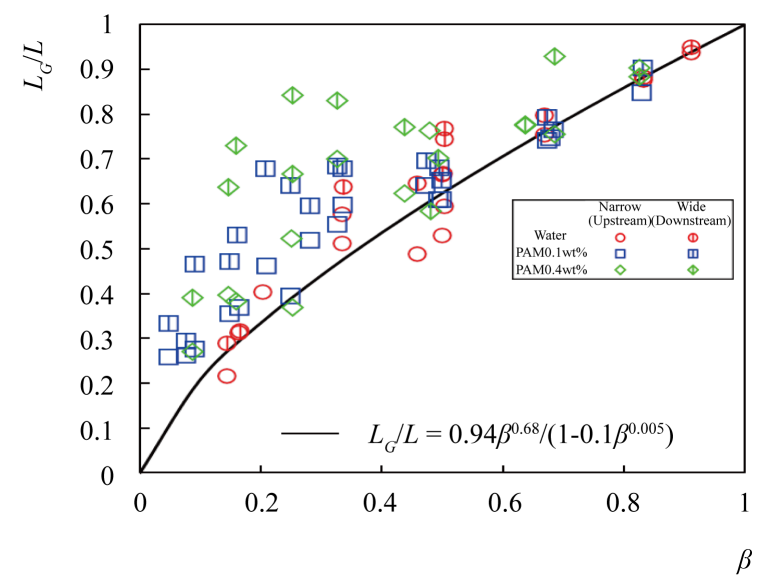

(b)

Figure 10. Bubble length. (a) $L_{G} / L$ vs. $\alpha$; (b) $L_{G} / L$ vs. $\beta$. 


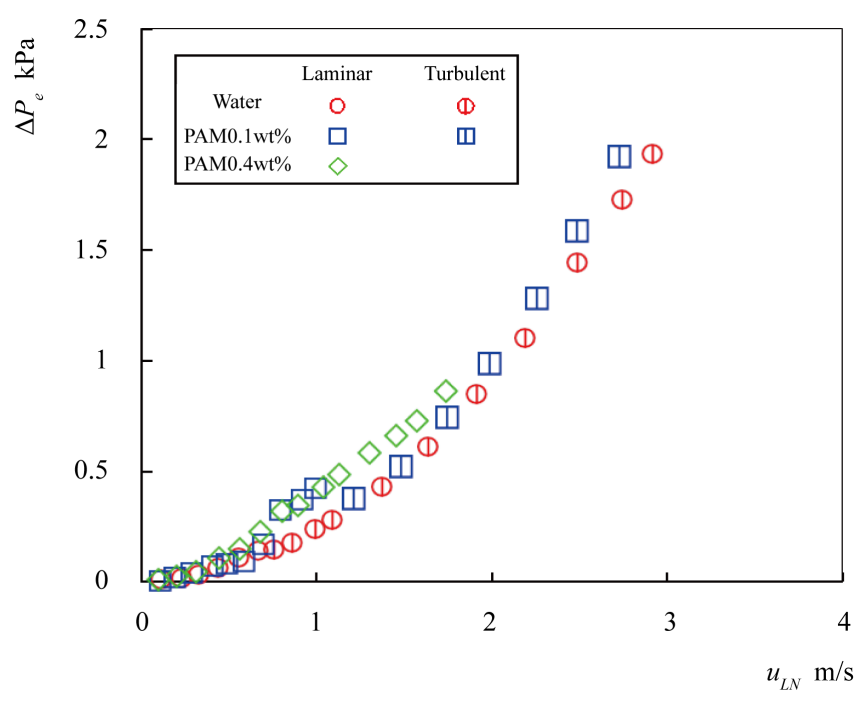

Figure 11. Single-phase pressure change at expansion.

The resulting $k_{e, I}$ data are plotted in Figure 12. The broken line shows the calculation by Borda-Carnot's formula $\left(=\left(1-\sigma_{A}\right)^{2}\right)$, while the solid line shows the calculation by Miyagawa et al.'s correlation [24]. As seen in the figure, the data on $k_{e, I}$ gradually approachto the calculation lines with the increase in $R e_{N}$, and the data in turbulent for water become almost constant nearby the calculation line by Miyagawa et al.'s correlation [24].

Figure 13(a) and Figure 13(b) show the present two-phase frictional pressure drop data for the channels upstream and downstream from the expansion, $\left(\mathrm{d} P_{f} / \mathrm{d} z\right)_{T P}$, against the gas volumetric flux, $j_{G}$. In general, the pressure gradient increases with the gas volumetric flux, $j_{G}$, and the present two-phase frictional pressure drop data for both the channels increase with $j_{L}$ at a fixed $j_{G}$.

Frictional pressure drop data are commonly correlated with the following two-phase friction multiplier, $\phi_{L}^{2}$ (Lochhart \& Martinelli, [32]):

$$
\left(\frac{\mathrm{d} P_{f}}{\mathrm{~d} Z}\right)_{T P}=\phi_{L}^{2}\left(\frac{\mathrm{d} P_{f}}{\mathrm{~d} Z}\right)_{L},
$$

where $\left(\mathrm{d} P_{f} / \mathrm{d} z\right)_{L}$ is the frictional pressure drop when the liquid flows alone in the same channel. A widely used correlation for the friction multiplier is that proposed by Chisholm and Laird [33]:

$$
\phi_{L}^{2}=1+\frac{C}{X}+\frac{1}{X^{2}},
$$

where $X$ is the Lockhart-Martinelli parameter given by

$$
X^{2}=\frac{\left(\mathrm{d} P_{f} / \mathrm{dZ}\right)_{L}}{\left(\mathrm{~d} P_{f} / \mathrm{d} Z\right)_{G}},
$$

In Equation (17), $\left(\mathrm{d} P_{f} / \mathrm{dZ}\right)_{G}$ is the frictional pressure drop when the gas flows alone in the same channel.

Figure 14(a) and Figure 14(b) show $\phi_{L}^{2}$ data against $X$ for the channels upstream and downstream from the expansion. The dashed lines is the calculated curve by the following Mishima-Hibiki's $C$ correlation [27]:

$$
C=21\left(1-\mathrm{e}^{-0.319 D_{H}}\right)
$$

where $D_{H}$ is the hydraulic diameter of the channel in millimeter. The data are well correlated with the Lockhart-Martinelli parameter with the Mishima-Hibiki’s $C$ correlation [27].

Expansion pressure drop correlations for two-phase flows in literatures are tested against the present data. For evaluating the accuracy in prediction, the following absolute mean and root mean square errors are used. 


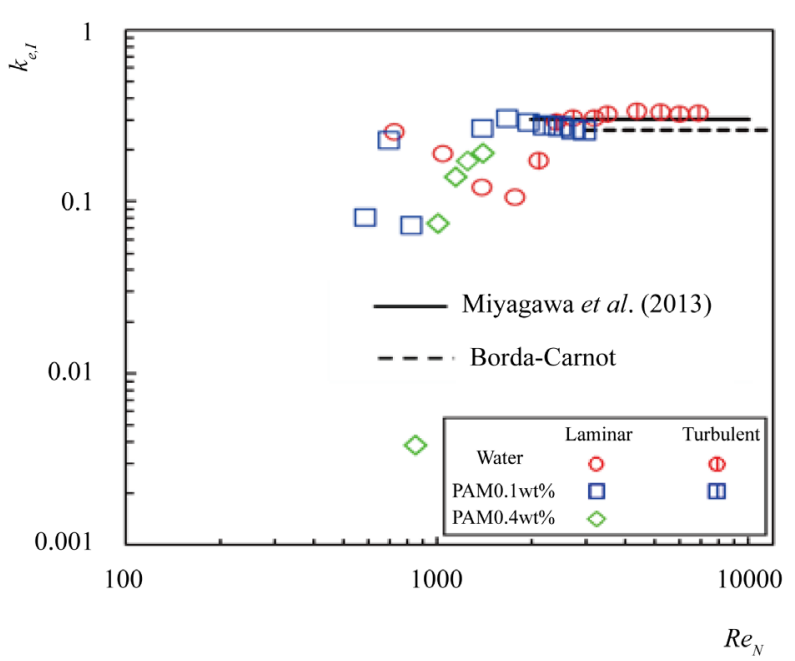

Figure 12. Expansion loss for single-phase flow.

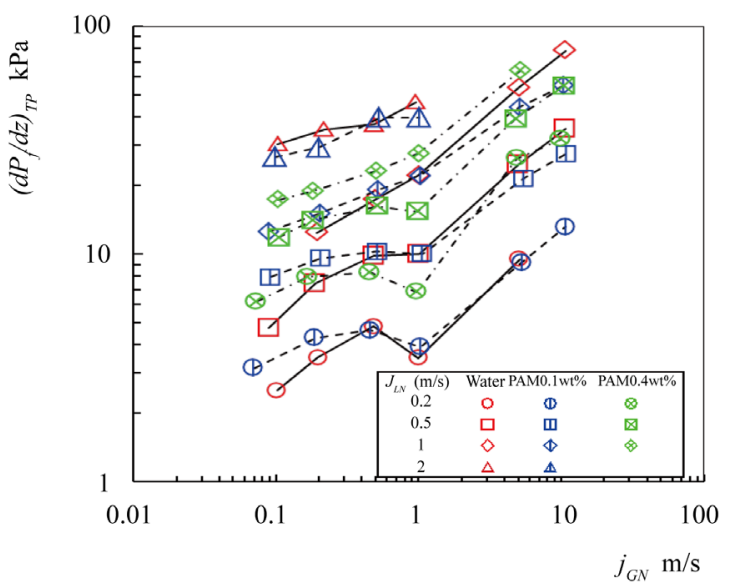

(a)

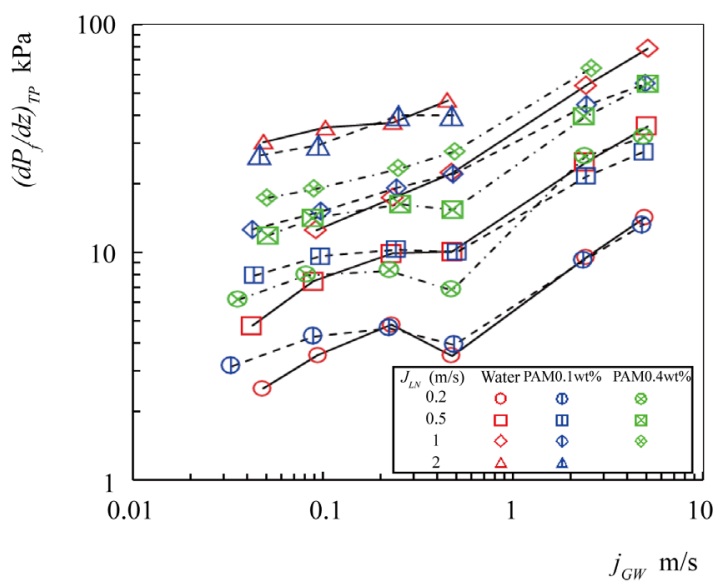

(b)

Figure 13. Frictional pressure drop data for two-phase flow in expansion. (water: wt\%: -.-.- ).

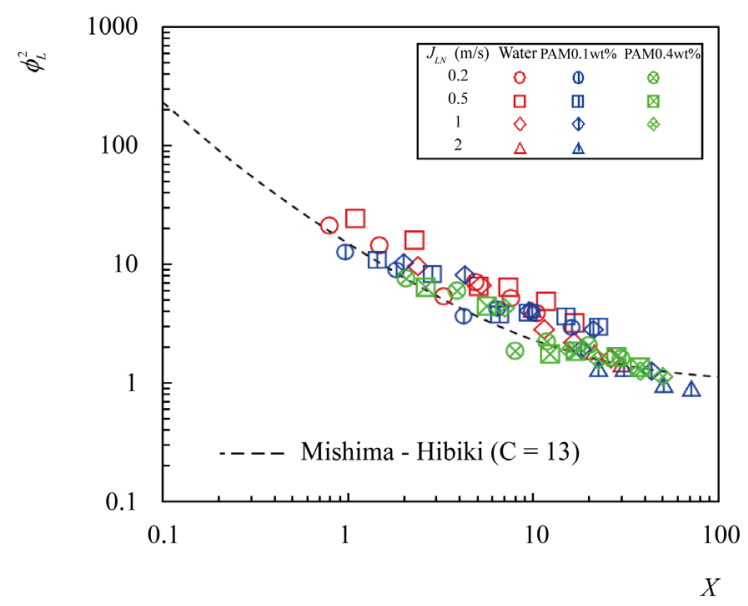

(a)

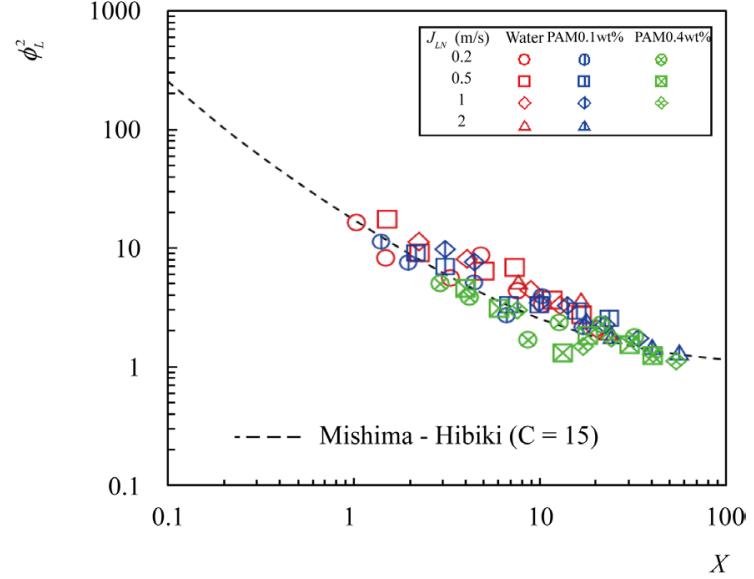

(b)

Figure 14. Two-phase frictional multiplier data against Lockhart \& Martinelli parameter for expansion channel. (a) Upstream; (b) Downstream. 


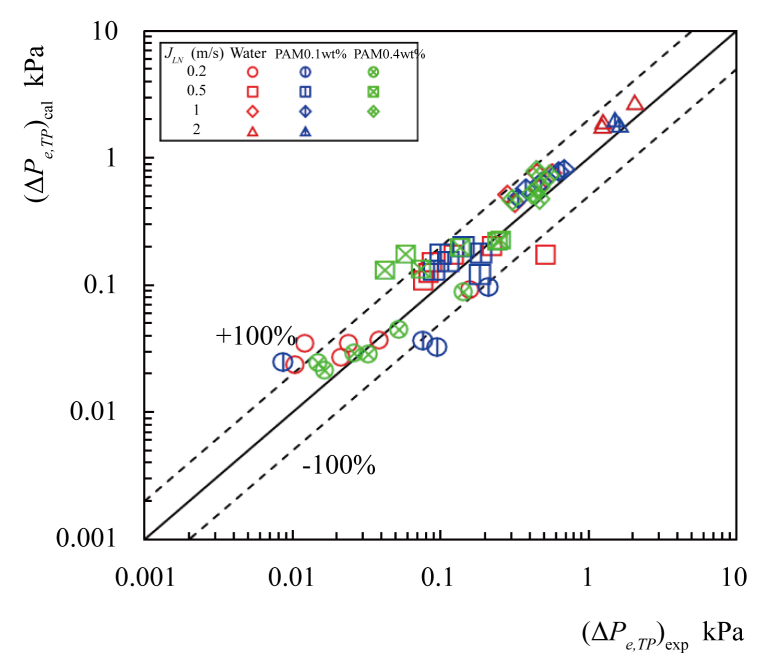

(a)

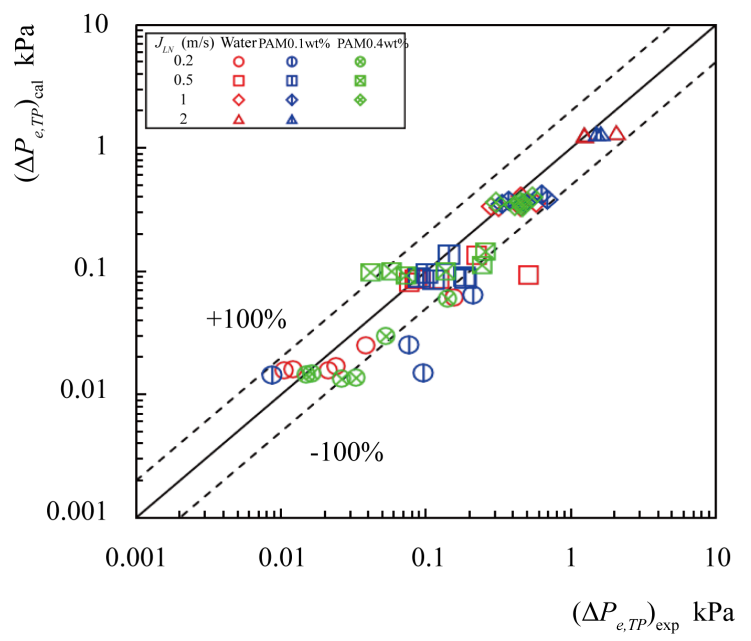

(c)

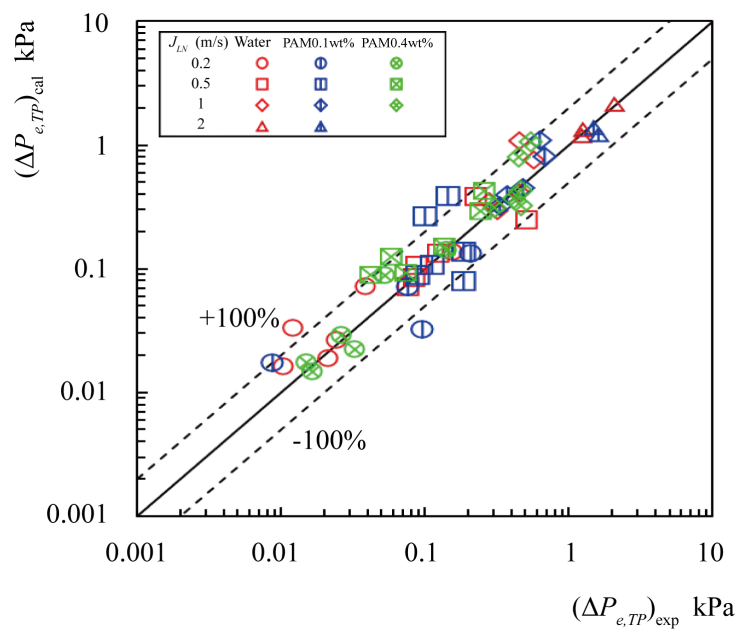

(e)

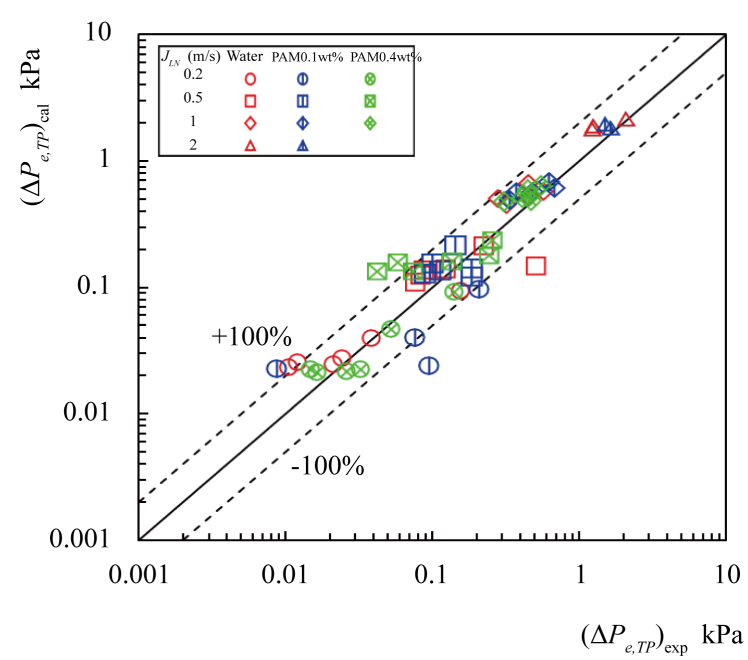

(b)

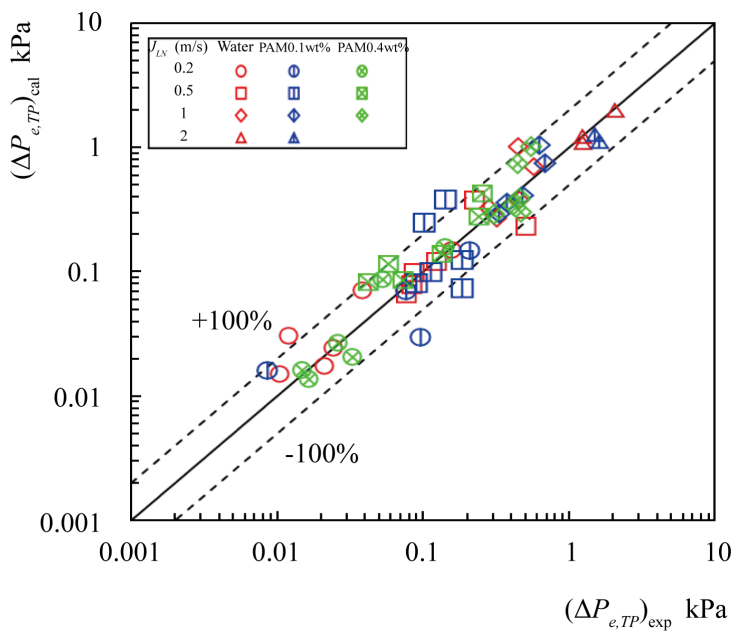

(d)

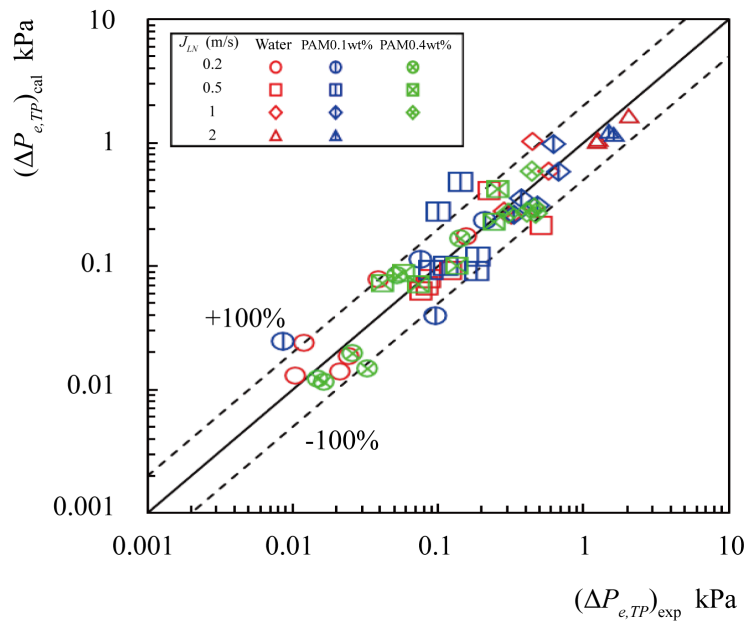

(f)

Figure 15. Comparison of $\Delta p_{e, T P}$ between experiment andcalculation by correlations. (a) Collier and Thome with Armad void fraction; (b) Collier and Thome with Schmidt-Friedel void fraction; (c) Wadle; (d) Schmidt-Friedel; (e) Modified Abdelall et al.; (f) Miyagawa et al. 
Table 5. Mean and RMS errors for sudden expansion pressure drop prediction.

\begin{tabular}{lcc}
\hline Correlation & $\boldsymbol{\varepsilon}_{M} \mathbf{k P a}$ & $\boldsymbol{\varepsilon}_{\mathrm{RMS}} \mathbf{k P a}$ \\
\hline Collier and Thome with Armad void fraction [34] & 0.147 & 0.181 \\
Collier and Thome with Schmidt-Friedel void fraction [34] & 0.118 & 0.149 \\
Wadle [35] & -0.026 & 0.151 \\
Schmidt-Friedel [36] & 0.028 & 0.178 \\
Modified Abdelall et al. [4] & 0.056 & 0.172 \\
Miyagawa et al. [24] & 0.008 & 0.128 \\
\hline
\end{tabular}

$$
\begin{aligned}
& \varepsilon_{M}=\frac{1}{n} \sum_{i=1}^{n}\left[\left(\Delta P_{e t, T P}\right)_{c a l}-\left(\Delta P_{e t, T P}\right)_{\exp }\right] P a \\
& \varepsilon_{R M S}=\sqrt{\frac{1}{n-1} \sum_{i=1}^{n}\left[\left(\Delta P_{e t, T P}\right)_{c a l}-\left(\Delta P_{e t, T P}\right)_{\exp }\right]^{2}} P a
\end{aligned}
$$

Table 5 lists the $\varepsilon_{M}$ and the $\varepsilon_{R M S}$ of six correlations against the present data. Miyagawa et al.'s correlation [24] gives the best prediction. Figures 15(a)-(f) show a comparison of the two-phase pressure change due to the expansion between experiment and calculations. Most of the data could be well predicted by these correlations within $100 \%$ in the relative error.

\section{Conclusions}

Non-Newtonian two-phase flow characteristics across sudden expansion in horizontal rectangular minichannel have been studied experimentally. Main findings are as follows:

1) The two-phase flow patterns were classified into bubble flow, slug flow and annular flow, irrespective of the difference of the test liquid. The bubble flow regime was narrowed in PAM $0.4 \mathrm{wt} \%$ case.

2) All the bubble velocity data were higher than that calculated by homogenous flow model, and the highest values were recorded in the PAM $0.4 \mathrm{wt} \%$ case. The calculations of bubble velocity by the drift flux model with Miyagawa et al.'s correlation [24] agreed with the present data within root mean square errors of $20 \%$.

3) The void fraction data for the present air-PAM 0.4 wt \% flows were about $20 \%$ lower than those for the air-water flows. The void fraction data were used to test six correlations in literatures. Modified Kawahara et al.'s [29] and Schmidt \& Friedel's correlations [30] gave better prediction than the others for the narrow channel, while Zhang et al.'s correlation [28] for the wide channel.

4) The bubble length data for both the upstream and the downstream channels were longer for air-PAM flow case than air-water one, especially for PAM $0.4 \mathrm{wt} \%$.

5) The single-phase pressure change data due to expansion, $\Delta P_{e}$, increased with the mean velocity of liquid in narrow channel, $u_{L N}$. The irreversible expansion pressure loss coefficient data, $k_{e, I}$, gradually approached to the calculations by Borda-Carnot's formula and Miyagawa et al.'s correlation for turbulent flow [24] with the increase in $R e_{N}$.

6) The two-phase frictional pressure dropin the channels for upstream and downstream from the expansion, $\left(\mathrm{d} P_{f} / \mathrm{dz}\right)_{T P}$, increased with the gas volumetric fluxand with the liquid volumetric flux.

7) Two-phase friction multiplier data were well correlated with the Lockhart-Martinelli parameter with Mishima-Hibiki's $C$ correlation [27].

8) The two-phase expansion pressure drop data were used to test six correlations in literatures, and Miyagawa et al.'s correlation [24] gave the best prediction.

\section{Acknowledgements}

The authors deeply appreciate DIKTI of Indonesian government and State Polytechnic of Cilacap for the fel- 
lowship and the permission to Mr. Agus Santoso to study in Kumamoto University. Appreciation is also to Mr. Miyagawa for his fruitful discussions and advise.

\section{References}

[1] Yang, Z.C., Bi, Q.C., Liu, B. and Huang, K.X. (2010) Nitrogen/Non-Newtonian Fluid Two-Phase Upward Flow in Non-Circular Microchannels. International Journal of Multiphase Flow, 36, 60-70. http://dx.doi.org/10.1016/j.ijmultiphaseflow.2009.07.011

[2] Sadatomi, M., Miyagawa, S., Santoso, B. and Kawahara, A. (2013) Air-Water Two-Phase Flow through U-Bend, Sudden Expansion and Sudden Contraction in Rectangular Mini-Channels. WIT Transactions on Engineering Sciences, 79, 63-75. http://dx.doi.org/10.2495/MPF130061

[3] Kawahara, A., Mansour, M.H., Sadatomi, M., Law, W.Z., Kurihara, H. and Kusumaningsih, H. (2015) Characteristics of Gas-Liquid Two-Phase Flows through a Sudden Contraction in Rectangular Microchannels. Experimental Thermal and Fluid Science, 66, 243-253. http://dx.doi.org/10.1016/j.expthermflusci.2015.03.030

[4] Abdelall, F.F., Hahn, G., Ghiaasiaan, S.M. and Sadowski, D.L. (2005) Pressure Drop Caused by Abrupt Flow Area Changes in Small Channels. Experimental Thermal and Fluid Science, 29, 425-434. http://dx.doi.org/10.1016/j.expthermflusci.2004.05.001

[5] Chen, I.Y., Chu, M.C., Liaw, J.S. and Wang, C.C. (2008) Two-Phase Flow Characteristics across Sudden Contraction in Small Rectangular Channels. Experimental Thermal and Fluid Science, 32, 1609-1619. http://dx.doi.org/10.1016/j.expthermflusci.2008.05.009

[6] Padilla, M., Revellin, R. and Bonjour, J. (2013) Two-Phase Flow of HFO-1234yf, R-134a and R-410A in Sudden Contractions: Visualization, Pressure Drop Measurements and New Prediction Method. Experimental Thermal and Fluid Science, 47, 186-205. http://dx.doi.org/10.1016/j.expthermflusci.2013.01.015

[7] Fu, T., Wei, L., Zhu, C. and Ma, Y. (2015) Flow Patterns of Liquid-Liquid Two-Phase Flow in Non-Newtonian Fluids in Rectangular Microchannels. Chemichal Engineering and Processing: Process Intensification, 91, 114-120. http://dx.doi.org/10.1016/j.cep.2015.03.020

[8] Link, F.B., Frey, S., Thompson, R.L. and Mendes, P.R.D.S. (2015) Plane Flow of Thixotropic Elasto-Viscoplastic Materials through a 1:4 Sudden Expansion. Journal of Non-Newtonian Fluid Mechanics, 220, 162-174. http://dx.doi.org/10.1016/j.jnnfm.2015.02.009

[9] Li, H., Wong, T.N., Skote, M. and Duan, F. (2014) Non-Newtonian Two-Phase Stratified Flow with Curved Interface through Horizontal and Inclined Pipes. International Journal of Heat and Heat and Mass Transfer, 74, 113-120. http://dx.doi.org/10.1016/j.ijheatmasstransfer.2014.02.052

[10] Picchi, D., Correra, S. and Poesio, P. (2014) Flow Pattern Transition, Pressure Gradient, Hold-Up Predictions in Gas/ Non-Newtonian Power-Law Fluid Stratified Flow. International Journal of Multiphase Flow, 63, 105-115. http://dx.doi.org/10.1016/j.ijmultiphaseflow.2014.03.005

[11] Tang, G.H., Lu, Y.B., Zhang, S.X., Wang, F.F. and Tao, W.Q. (2012) Experimental Investigation of Non-Newtonian Liquid Flow in Microchannels. Journal of Non-Newtonian Fluid Mechanics, 173-174, 21-29. http://dx.doi.org/10.1016/j.jnnfm.2012.02.001

[12] Mansour, M.H., Kawahara, A. and Sadatomi, M. (2015) Experimental Investigation of Gas-Non Newtonian Liquid Two-Phase Flows from T-Junction Mixer in Rectangular Microchannel. International journal of Multiphase Flow, 72, 263-274. http://dx.doi.org/10.1016/j.ijmultiphaseflow.2015.02.019

[13] Goto, D., Santoso, A., Takehira, T., Aslam, A., Kawahara, A. and Sadatomi, M. (2016) Pressure Drop for Gas and Non-Newtonian Liquid Two-Phase Flows Across Sudden Expansion in Horizontal Rectangular Mini-Channel. Journal of Mechanical Engineering and Automation, 6, 51-57.

[14] Santoso, A., Goto, D., Takehira, T., Kawahara, A. and Sadatomi, M. (2015) Single-Phase and Two-Phase Pressure Drops Across Sudden Contraction in Horizontal Rectangular Minichannel. International Journal of Advancements in Mechanical and Aeronautical Engineering, 2, 195-199.

[15] Santoso, A., Goto, D., Takehira, T., Kawahara, A. and Sadatomi, M. (2016) Two-Phase Flow Characteristics across Sudden Contraction in Horizontal Rectangular Minichannel. Journal of Mechanical Engineering and Automation, 6, 58-64.

[16] Santoso, A., Goto, D., Takehira, T., Kawahara, A. and Sadatomi, M. (2016) Experimental Study on Two-Phase Pressure Drop through Sudden Expansion and Sudden Contraction in Horizontal Rectangular Minichannel. The 27th International Symposium on Transport Phenomena, Honolulu, 20-23 September 2016.

[17] Chhabra, R., Farooqi, S.I. and Richardson, J.F. (1984) Isothermal Two-Phase Flow of Air and Aqueous Polymer Solutions in a Smooth Horizontal Pipe. Chemical Engineering Research and Design, 62, 22-32.

[18] Farooqi, S.I. (1980) Rheological Behavior of Kaolin Suspensions in Water and Water Glycerol Mixtures. Transactions 
of the Institution of Chemical Engineering, 58, 116-124.

[19] Kays, W.M. (1950) Loss Coefficient for Abrupt Changes in Flow Cross Section with Reynolds Number Flow in Single and Multiple Mube Systems. Transactions of the American Society of Mechanical Engineers, 72, 1067-1074.

[20] Sadatomi, M., Sato, Y. and Saruwatari, S. (1982) Two-Phase Flow in Vertical Noncircular Channels. International Journal of Multiphase Flow, 8, 641-655. http://dx.doi.org/10.1016/0301-9322(82)90068-4

[21] Shah, R.K. and London, A.L. (1978) Laminar Flow Forced Convection in Ducts. Academic Press, New York.

[22] Zuber, N. and Findlay, J.A. (1968) Average Volumetric Concentration in Two-Phase Flow System. Journal of Heat Transfer, 87, 453-468. http://dx.doi.org/10.1115/1.3689137

[23] Kawahara, A., Sadatomi, M., Nei, K. and Matsuo, H. (2011) Characteristics of Two-Phase Flows in a Rectangular Microchannel with a T-Juction Type Gas-Liquid Mixer. Heat Transfer Engineering, 32, 585-594. http://dx.doi.org/10.1080/01457632.2010.509752

[24] Miyagawa, S. (2014) Study on Characteristics of Gas-Liquid Two Phase Flow through Singularities. Master Thesis, Kumamoto University, Kumamoto.

[25] Armand, A.A. (1946) The Resistance During The Movement of a Two-Phase System in Horizontal Pipes. Izvestia Vses. Teplotekh. Inst., 1, 16-23.

[26] Spedding, P.L. and Chen, J.J.J. (1986) Hold-Up in Multiphase Flow. Encyclopedia of Fluid Mechanics, 3, $492-531$.

[27] Mishima, K. and Hibiki, T. (1996) Some Characteristics of Air-Water Two-Phase Flow in Small Diameter Vertical Tubes. International Journal Multiphase Flow, 22, 703-712. http://dx.doi.org/10.1016/0301-9322(96)00010-9

[28] Zhang, W., Hibiki, T. and Mishima, K. (2010) Correlations of Two-Phase Frictional Pressure Drop and Void Fraction in Mini-Channel. International Journal of Heat and Mass Transfer, 53, 453-465. http://dx.doi.org/10.1016/j.ijheatmasstransfer.2009.09.011

[29] Kawahara, A., Sadatomi, M. and Shimokawa, S. (2011) Bubble and Liquid Slug Length for Two-Phase Flows in a Rectangular Microchannel with T-Junction Type Gas-Liquid Mixer. 22nd International Symposium on Transport Phenomena, Delft, 8-11 November 2011.

[30] Schmidt, J. and Friedel, L. (1997) Two-Phase Flow Pressure Drop across Sudden Contractions in Duct Areas. International Journal of Multiphase Flow, 23, 283-299. http://dx.doi.org/10.1016/S0301-9322(96)00056-0

[31] Kanezaki, K. (1981) Slug Flow in Vertical Minichannel. Master Thesis, Kumamoto University, Kumamoto.

[32] Lockhart, R.W. and Martinelli, R.C. (1949) Proposed Correlation of Data for Isothermal Two-Phase, Two-Component Flow in Pipes. Chemical Engineering Progress, 45, 38-48.

[33] Chisholm, D. and Laird, A.D.K. (1958) Two-Phase Flow in Rough Tubes. Transactions of the American Society of Mechanical Engineers, 80, 276-286.

[34] Collier, J.G. and Thome, J.R. (1994) Convective Boiling and Condensation. 3rd Edition, Oxford, New York, $109-111$.

[35] Wadle, M. (1989) A New Formula for the Pressure Recovery in an Abrupt Diffuser. International Journal of Multiphase Flow, 15, 241-256. http://dx.doi.org/10.1016/0301-9322(89)90073-6

[36] Schmidt, J. and Friedel, L. (1995) Two-Phase Flow Pressure Change Across Sudden Expansions in Duct Areas. Chemical Engineering Communications, 141-142, 175-190. http://dx.doi.org/10.1080/00986449608936415 


\section{Submit or recommend next manuscript to SCIRP and we will provide best service for you:}

Accepting pre-submission inquiries through Email, Facebook, LinkedIn, Twitter, etc.

A wide selection of journals (inclusive of 9 subjects, more than 200 journals)

Providing 24-hour high-quality service

User-friendly online submission system

Fair and swift peer-review system

Efficient typesetting and proofreading procedure

Display of the result of downloads and visits, as well as the number of cited articles

Maximum dissemination of your research work

Submit your manuscript at: http://papersubmission.scirp.org/ 